\title{
Contribuições de Henri Wallon à relação cognição e afetividade na educação
}

\section{Contributions from Henri Wallon to the relationship between cognition and affectivity in education}

\author{
Aurino Lima Ferreira ${ }^{1}$ \\ Nadja Maria Acioly-Régnier ${ }^{2}$
}

\begin{abstract}
RESUMO
O presente artigo versa sobre as contribuições de Henri Wallon à relação cognição e afetividade na educação. Situa e define os complexos afetivos e cognitivos na teoria waloniana e destaca a noção de pessoa engajada como síntese fundamental para o entendimento da relação entre afetividade e cognição no campo educacional. Busca ainda apontar a importância da visão dialética e humanista da pessoa completa de Wallon para as práticas educacionais e retoma a ideia de "circularidade fundamental” de Francisco Varela para atualizar a visão de Wallon sobre a não separatividade entre homem e mundo.

Palavras-chave: afetividade; cognição; educação; Henri Wallon; circularidade fundamental.
\end{abstract}

1 Professor do Departamento de Psicologia e Orientação Educacionais - Universidade Federal de Pernambuco (UFPE); pesquisador associado do Pôle de recherche école \& société - Institut Universitaire de Formation des Maîtres de Lyon - IUFM - France.

2 Doutora em Psicologia - Université René Descartes - Paris V Sorbonne. Responsável do setor Pesquisa do Departamento de Ciências Humanas e Sociais do Institut Universitaire de Formation des Maîtres de Lyon-Pôle école et société - Université Claude Bernard Lyon 1 - France Laboratoire SIS (Santé Individu Société) - Université Lumière Lyon 2 - France. E-mail: Acioly. regnier@wanadoo.fr. 


\begin{abstract}
This paper focuses on the contributions from Henri Wallon about the relationship between cognition and affectivity in the education. It also defines the complex interdependency between affective and cognitive dimensions of such theory and emphasizes the notion of engaged person as a fundamental synthesis to understanding the relationship between affectivity and cognition in the educational field. This article also highlights the importance of dialectical and humanist view of integral person for educational practices and it incorporates the idea of "fundamental circularity" of Francisco Varela aiming to updating the view of Wallon about non-separateness between human beings and world.

Keywords: affectivity; cognition; education; Henri Wallon; fundamental circularity.
\end{abstract}

\title{
Introdução
}

Um dos desafios da educação no século XXI diz respeito à questão da multietnicidade, da convivência plural e democrática e da unidade na diversidade. Desafio que extrapola a educação em sentido estrito, envolvendo a sociedade e requerendo reflexões mais amplas no que diz respeito às metas da formação humana. Hoje, as relações de sociabilidade são de desconfiança, violência e agressão e os cidadãos emergem como "inimigos potenciais" que disputam conosco um lugar no Mercado de Trabalho e na divisão de bens e serviços. Ao lado de tantos desafios que a educação deve se defrontar - o analfabetismo, a evasão escolar, a educação de jovens e adultos etc. -, a questão da relação entre cognição e afetividade, ao lado da violência, sem dúvida, constitui um ponto focal da agenda educativa no século XXI.

Uma agenda repleta de ambivalências e desafios. De um lado, temos cada vez mais desvelado o lugar opressor das instituições educacionais no processo de formação humana, como foi apontado nas críticas contundentes de Foucault (1995), que destaca uma simetria entre os modelos das celas nos conventos, quartéis, hospitais, fábricas e o das escolas. Na escola, o lugar de cada um, a ordem nas fileiras, a repartição das tarefas, os gestos mais úteis, são postos não só para tornar as pessoas mais submissas, mas também para garantir uma melhor economia do tempo e dos gestos.

Por outro lado, a possibilidade de resistência via escola tem sido levantada por muitos autores, pondo em cheque as concepções neoliberais a respeito dos 
fins da educação, como a tarefa prática de preparar os indivíduos para a vida social. Nesse sentido, as palavras de Neidson Rodrigues (2001, p. 253-254) permanecem plenamente atuais:

[...] Na medida em que os meios e as formas tradicionais de Educação acham-se de tal modo corroídos, começam a ser direcionados para a Escola os olhares dos povos, na esperança de que esta exerça uma função Educativa e não apenas a da Escolarização. Somente que será necessária uma outra visão da Escola, dos conteúdos escolares, do papel dos educadores e da relação da Escola com a sociedade.

As crianças serão enviadas para a Escola cada vez mais cedo e nela permanecerão por um tempo mais extenso. E isso não será porque há um mundo novo de informações a ser processado e, sim, porque a Escola deverá exercer o tradicional papel das famílias, das comunidades, da Igreja, e ainda, o que lhe era próprio: desenvolver conhecimentos e habilidades. Ela deverá se ocupar com a formação integral do ser humano e terá como missão suprema a formação do sujeito ético.

Uma educação comprometida com uma agenda reflexiva busca ampliar e resgatar os fundamentos da razão formativa, a saber: a humanização. Isso implica novos desafios para educação e para escola. Dentre eles podemos incluir o questionamento acerca do lugar da afetividade e suas relações com a cognição no campo educacional. Nesse sentido, destacamos dois pequenos trechos de textos que revelam a complexidade e pertinência desse questionamento nos processos educacionais na atualidade. Estes textos foram produzidos por adolescentes que faziam parte de uma experiência de educação não formal acompanhada durante a tese de doutorado de Ferreira (2007).

O primeiro texto foi produzido por uma aluna, a pedido da professora, durante uma aula, na qual ela não conseguia conter sua irritação, movimentandose de forma inquieta pela sala. O segundo texto emergiu durante uma aula de matemática na qual o aluno falava de sua indignação e raiva por ter sido submetido a uma situação de violência antes de chegar à escola ${ }^{3}$.

Por mim eu matava, tocava fogo e depois jogava o resto no mar. Não gosto dele, nunca gostei. Minha mãe diz que ele é meu pai, mas não considero. Saber fazer, soube. Às vezes, vai lá em casa, não mora mais com minha mãe, e vai dando um de valente, que "butar" ordem, "butar" moral [...]

3 A transcrição preserva o estilo oral da produção. 
Ele veio dá um tapa na minha cara, minha mãe se meteu, se tivesse dado ele ia vê... Pedi uma arma ao pessoal da esquina só esperando ele dá-lhe, tava doida que ele desse, não dormi de noite só esperando, ele ia logo, logo pra debaixo do chão (Gudimylla, 13 anos).

Eu vinha para o curso, aí a policia mandou parar, eu não tinha nada "haver”, estava passando na esquina da escola Costa Porto, ai eles mandou ficar de costa na parede, revistou dando tapa e dizendo gracinha, e ai foi logo perguntando onde tava o roubo. Vocês são ladrão, eu sei, a gente escutava e ficava calado. Aí mandou a gente baixar as calças e ficar nu na parede ai depois mandou a gente ir embora (Lucas, 14 anos).

A experiência emblemática vivida por esses dois adolescentes aponta para a presença viva da afetividade no cenário educacional, uma presença que não se pode mais ignorar, pois a experiência indica que o afeto influencia as relações e os processos de aprendizagem, requerendo visões inclusivas e capazes de resgatar a dimensão de cuidado necessária ao processo educativo.

A escola como o lugar privilegiado para formação exclusiva da cognição tem encontrado desafios antes não imaginados, pois em que pesem as tentativas de impedir o surgimento dos afetos no ato educativo, a sua presença aparece nas atividades propostas, nas relações que são estabelecidas, nos ditos e não ditos que povoam o imaginário escolar, convidando-nos a continuarmos refletindo e repensando o seu lugar nos processos formativos.

Assim, o objetivo central deste texto é apresentar algumas das principais contribuições da teoria walloniana para favorecer a compreensão da relação cognição e afetividade no campo educacional. Nesse sentido, faremos uma breve justificativa sobre a escolha de Wallon, seguido de uma discussão sobre a afetividade e a cognição em sua teoria, e por fim apresentaremos uma proposição de que esses dois conjuntos funcionais são faces de uma mesma moeda: a pessoa.

\section{Por que Henri Wallon?}

A escolha de Henri Wallon para iluminar a questão da relação cognição e afetividade e suas implicações educacionais decorre de várias razões:

- Sua concepção psicogenética dialética do desenvolvimento apresenta uma grande contribuição para a compreensão do humano como pessoa integral, ajudando na superação da clássica divisão mente/corpo presente na cultura 
ocidental e dos seus múltiplos desdobramentos;

- Engloba em um movimento dialético a afetividade, a cognição e os níveis biológicos e socioculturais e também traz contribuições para o processo ensino-aprendizagem;

- Valoriza a relação professor-aluno e a escola como elementos fundamentais no processo de desenvolvimento da pessoa completa;

- Tendo um estreito contato tanto com a psicologia como com a educação, aponta para a relação bidirecional entre essas disciplinas, antecipando as novas perspectivas de psicologia da educação conforme apresentada por Coll, Palácios e Marchesi (1995);

- Apresenta uma visão política de uma educação mais justa para uma sociedade democrática, expressa no projeto Langevin-Wallon, fruto de três anos de trabalho (1945-1947), que buscava repensar o sistema de ensino francês a partir dos princípios norteadores da Justiça e Dignidade, valorizando ainda a cultura geral e destacando a importância de primeiro ter-se orientação escolar e somente depois a profissional.

Dessa forma, a teoria walloniana traz grandes contribuições para o entendimento das relações entre educando e educador, além de situar a escola como um meio fundamental no desenvolvimento desses sujeitos. A noção de domínios funcionais "entre os quais vai se distribuir o estudo das etapas que a criança percorre serão, portanto, os da afetividade, do ato motor, do conhecimento e da pessoa” (WALLON, 1995, p. 117). Eles são construtos teóricos que ajudam na compreensão dos processos de desenvolvimento e são postos como indicadores na condução dos processos ensino/aprendizagem.

Nas palavras de Wallon (2007, p. 113): “As exigências da descrição obrigam a tratar de forma distinta alguns grandes conjuntos funcionais, o que certamente não pode se feito sem certa artificialidade.”. Assim, a seguir apresentaremos os dois conjuntos funcionais, afetividade e cognição, destacando que esta apresentação separada é meramente didática, pois esses conjuntos operam de forma interdependente.

\section{Afetividade em Wallon}

No campo educacional, o interesse pelo estudo da afetividade é um fenômeno relativamente recente. A herança positivista nessa área dificultava a inclusão dessa temática, classificada geralmente como "não científica" ou posta como não relevante, sendo muitas vezes marginalizada ou usada de maneira 
generalizada para justificar as dificuldades em lidar com aqueles que rompiam as barreiras das regras escolares.

Como aponta Kirouac (1994), só a partir da década de 1970 temos o surgimento dos estudos empíricos que passam a incluir as variáveis mais subjetivas, como a afetividade, configurando um maior interesse científico nessa área. Sem, contudo, abrir espaço para inclusão da relação entre afetividade e cognição, mesmo que a demanda das queixas educacionais fossem insistentemente levantadas a partir do referencial afetivo: "não aprendem porque não tem apoio afetivo em casa”, "os pais estão se separando e as notas revelam isto”, "não conseguem prestar a atenção, estão tomados pelos hormônios da aborrecência".

Os anos noventa do século passado foram marcados pela emergência midiática da "inteligência emocional" de Goleman (1995), que mesmo retomando o debate sobre a afetividade e cognição, a partir da noção de inteligência emocional, traz uma junção de conceitos, como, por exemplo, sobrepõe emoção e sentimento, dificultando uma maior definição dos conceitos chaves que permeiam essa área, tais como emoção, sentimento, paixão e estados de espírito.

Uma das contribuições centrais de Wallon está em dispor de uma conceituação diferencial sobre emoção, sentimentos e paixão, incluindo todas essas manifestações como um desdobramento de um domínio funcional mais abrangente: a afetividade, sem contudo, reduzi-los uns aos outros. Assim podemos definir a afetividade como o domínio funcional que apresenta diferentes manifestações que irão se complexificando ao longo do desenvolvimento e que emergem de uma base eminentemente orgânica até alcançarem relações dinâmicas com a cognição, como pode ser visto nos sentimentos.

Ao apontar a base orgânica da afetividade, a teoria walloniana resgata o orgânico na formação da pessoa, ao mesmo tempo em que indica que o meio social vai gradativamente transformando esta afetividade orgânica, moldando-a e tornando suas manifestações cada vez mais sociais. Assim, temos um laço de união entre o corpo e o meio social, formando o que na tradição filosófica francesa denomina-se entre-deux, ou seja, um campo que se forma no limiar das dualidades, no qual: "O mundo é inseparável do sujeito, mas de um sujeito que não é senão projeto do mundo, e o sujeito é inseparável do mundo, mas de um mundo que ele mesmo projeta.” (MERLEAU-PONTY, 1999, p. 576).

Essa concepção da relação entre homem e mundo e a própria compreensão dos principais conjuntos funcionais que ajudam a compreender a formação da pessoa total encontra-se espalhado em diversas obras de Wallon. Em Les origines du caractère chez l'enfant (1934). Esse autor destaca a importância da afetividade no processo de desenvolvimento da personalidade da criança, que se iniciaria de forma sincrética e gradativamente adquiriria contornos mais nítidos através dos processos de diferenciação. 
No livro A evolução psicológica da criança, Wallon (2007) destaca a ligação indissolúvel entre o desenvolvimento psíquico e o desenvolvimento biológico do individuo, afirmando que não existe preponderância do desenvolvimento psíquico sobre o desenvolvimento biológico, mas ação recíproca. Há, portanto, uma incessante ação recíproca do ser vivo e de seu meio.

Wallon concordava com a teoria freudiana, e com os teóricos do desenvolvimento da época, de que o recém-nascido, em decorrência de sua indiferenciação somato-psíquica, expressava a afetividade de forma sincrética a partir das experiências de bem-estar ou mal-estar propiciadas pelas relações do organismo com o meio interno e externo. $\mathrm{O}$ seio materno representa este momento no qual o saciar da fome mescla-se com o surgimento das primeiras experiências amorosas. E ao longo do desenvolvimento a afetividade vai alternando com o conjunto funcional cognitivo em um movimento dialético ora centrípeto e ora centrífugo, e que inclui ainda o conjunto motor, como base de sustentação e expressão.

Assim, podemos compreender a afetividade, de forma abrangente, como um conjunto funcional que emerge do orgânico e adquire um status social na relação com o outro e que é uma dimensão fundante na formação da pessoa completa.

\section{Cognição em Wallon}

Assim como a afetividade, a cognição é um elemento fundamental na psicogênese da pessoa completa, sendo o seu desenvolvimento também relacionado às bases biológicas e suas constantes interações com o meio. De maneira que é importante visualizá-los em constante interação quando do surgimento da inteligência. Refletindo sobre as origens orgânicas da inteligência, Wallon (2008, p. 117) destaca:

O que permite à inteligência esta transferência do plano motor para o plano especulativo não pode evidentemente ser explicado, no desenvolvimento do indivíduo, pelo simples fato de suas experiências motoras combinarem-se entre si para melhor adaptar-se exigências múltiplas e instáveis do real. O que está em jogo são as aptidões da espécie, particularmente as que fazem do homem um ser essencialmente social. 
E em seu livro Do ato ao pensamento (2008) retoma a tese sobre a base orgânica no surgimento do pensamento, destacando que: “[...] do ato motor à representação houve transposição, sublimação desta intuição que, de incluída nas relações entre o organismo e o meio físico, se tornou esquematização mental. A evolução ocorrida entre o ato e o pensamento explica-se simultaneamente pelo oposto e pelo mesmo.” (WALLON, 2008, p. 224).

Assim, em Wallon, a cognição, como a afetividade, brota das entranhas orgânicas e vai adquirindo complexidade e diferenciação na relação dialética com o social. Em A evolução psicológica da criança, ele aponta a aquisição da linguagem como um fator primordial para o desenvolvimento da cognição, apresentando os estudos comparativos de Kellog e sua esposa ${ }^{4}$ para marcar os avanços cognitivos presentes em crianças quando comparadas a macacos.

Segundo a teoria walloniana, o domínio funcional cognitivo oferece um conjunto de funções que permite: "[...] identificar e definir [...] significações, classificá-las, dissociá-las, reuni-las, confrontar suas relações lógicas e experimentais, tentar reconstruir por meio delas qual pode ser a estrutura das coisas” (WALLON, 2007, p. 117).

Nas palavras de Mahoney e Almeida (2005, p. 18), esse domínio funcional: "[...] permite a aquisição e a manutenção do conhecimento por meio de imagens, noções, ideias e representações. É ele que permite ainda registrar e rever o passado, fixar e analisar o presente e projetar futuros possíveis e imaginários.".

Esse conjunto também parte do sincretismo, com seu amorfismo e indiferenciação, até as suas manifestações mais complexas, expressas nos bens simbólicos e na consciência de si. Pode-se apreender da leitura de Wallon que as funções psicológicas superiores desenvolvem-se a partir das dimensões motora e afetiva. E que esta se alterna e conflitua com a afetividade, em especial com a emoção. Contudo a cognição permanece inseparável da afetividade, devendo no adulto alcançar um equilíbrio dinâmico.

\section{Cognição e Afetividade: duas faces de uma mesma Pessoa}

A noção de pessoa apresentada por Wallon aponta para uma síntese dos conjuntos funcionais (afetivo, motor e cognitivo) e para integração dinâmica entre o orgânico e o social. Sua posição teórica era contrária à compreensão do humano de forma fragmentada.

4 Na obra consultada, Wallon descreve dessa maneira os autores. 
É contra a natureza tratar a criança fragmentariamente. Em cada idade, ela constitui um conjunto indissociável e original. Na sucessão de suas idades, ela é um único e mesmo ser em curso de metamorfoses. Feita de contrastes e de conflitos, a sua unidade será por isso ainda mais susceptível de desenvolvimento e de novidade. (WALLON, 2007, p. 198).

Contra a fragmentação, ele trata o humano em sua infância, não como um "vir a ser" incompleto, "um menor" a quem falta algo próprio do adulto. Atribui à criança um estatuto de pessoa que deve ser entendida naquele momento evolutivo no qual se encontra. Essa posição walloniana implica repensarmos as práticas e teorias em educação que põem a criança em uma posição objetificante e não como sujeitos de direito e desejo.

Wallon situa a noção de pessoa como o conjunto funcional resultante da integração de suas dimensões, e cujo processo de desenvolvimento ocorre na integração do orgânico com o meio, que em sua teoria é sempre predominantemente social.

O desenvolvimento da pessoa como um ser completo não ocorre de forma linear e contínua, mas apresenta movimentos que implicam integração, conflitos e alternâncias na predominância dos conjuntos funcionais. No que diz respeito à afetividade e cognição, esses conjuntos revezam-se, em termos de prevalência, ao longo dos estágios de desenvolvimento. Nos estágios impulsivo-emocional, personalismo, puberdade e adolescência, nos quais predomina o movimento para si mesmo (força centrípeta) há uma maior prevalência do conjunto funcional afetivo, enquanto no sensório-motor e projetivo e categorial, nos quais o movimento se dá para fora, para o conhecimento do outro (força centrífuga), o predomínio é do conjunto funcional cognitivo.

Essa alternância de domínios funcionais não exclui a presença dos conjuntos não dominantes, pois estes continuam interagindo continuadamente entre si, formando a complexidade presente na personalidade da pessoa. Destacando como o conjunto funcional afetivo influencia o meio social e afeta o cognitivo, Wallon (1986, p. 146) aponta que:

[...] a coesão de reações, atitudes e sentimentos, que as emoções são capazes de realizar em um grupo, explica o papel que elas devem ter desempenhado nos primeiros tempos das sociedades humanas: ainda hoje são as emoções que criam um público, que animam uma multidão, por uma espécie de consentimento geral que escapa ao controle de cada um. Elas suscitam arrebatamentos coletivos capazes de escandalizar, por vezes, a razão individual. 
Contudo, como temos o afeto influenciando a cognição e por vezes até “escandalizando-a”, o trabalho com o cognitivo também pode oferecer à pessoa a possibilidade de manejo integrativo da afetividade. Como, por exemplo, na fala de Gudimylla, apresentada no inicio deste texto, temos expressado como os afetos vividos no espaço familiar (conflitos com a figura do pai) acompanharam a adolescente até a sala de aula e dificultaram a realização das atividades propostas. E como o seu reconhecimento, acolhimento e a possibilidade de expressá-lo através da escrita do diário, proposta pela educadora, possibilitou a sua inclusão.

A experiência da educadora no manejo da teoria walloniana e a sua conviç̧ão de que a tarefa educativa implica compreensão do humano como pessoa completa, possibilitou-a reconhecer como a presença dos afetos estava interferindo na aprendizagem da aluna e sem buscar reprimi-los, ou considerar que não seria de sua responsabilidade o seu manejo, ofereceu espaço para a entrada do cognitivo, como estruturador do afeto.

As situações de dor, perdas, sofrimentos, mortes, lutos e a violência vivida pelos alunos, como a apresentada por Lucas no início do texto, requerem do educador uma compreensão abrangente e integrativa do desenvolvimento, no qual as diversas faces do aluno enquanto pessoa possam ser contempladas, e não apenas uma visão unilateral que privilegia apenas uma dimensão ou conjunto funcional. Na proposta educativa walloniana, a integração é um conceito fundamental na formação do educando, e é claramente descrito por Mahoney (2008, p. 15):

O motor, o afetivo, o cognitivo, a pessoa, embora cada um desses aspectos tenha identidade estrutural e funcional diferenciada, estão tão integrados que cada um é parte constitutiva dos outros. Sua separação se faz necessária apenas para a descrição do processo. Uma das conseqüências dessa interpretação é de que qualquer atividade humana sempre interfere em todos eles. Qualquer atividade motora tem ressonâncias afetivas e cognitivas; toda disposição afetiva tem ressonâncias motoras e cognitivas; toda operação mental tem ressonâncias afetivas e motoras. E todas essas ressonâncias têm um impacto no quarto conjunto: a pessoa, que, ao mesmo tempo em que garante essa integração, é resultado dela.

Assim, a educação decorrente do estudo da teoria walloniana implica a inclusão de uma visão de pessoa completa e engajada. O termo engajado é tributário da filosofia francesa (MERLEAU-PONTY, 1962; 1969) e da luta política que busca não afastar o sujeito do mundo. Nesse sentido, apresentaremos as 
contribuições de Varela, Thompson e Rosch (2003) à noção de pessoa concreta e completa de Wallon com base na "circularidade fundamental”.

\section{A circularidade fundamental na formação da pessoa engajada}

Quando iniciamos a reflexão sobre as relações entre cognição e afetividade e suas implicações educacionais, deparamo-nos com a seguinte afirmação, adaptada de Varela, Thompson e Rosch (2003, p. 21):

O sujeito desperta em um mundo que não é projeção de sua mente. Nós simplesmente, nos descobrimos com ele; nós despertamos tanto para nós mesmos, quanto para o mundo que habitamos. Refletimos sobre esse mundo à medida que crescemos e vivemos. Mas refletimos sobre um mundo que não é feito, mas encontrado, e é também a estrutura que nos possibilita refletir sobre esse mundo. Então, ao nos debruçarmos sobre ele, nós nos encontramos em um círculo: estamos em um mundo que parece que já existia antes da reflexão ter-se iniciado, mas esse mundo não é separado de nós.

Essa visão de homem "inseparável do mundo" aproxima as ideias wallonianas das construções dos teóricos cognitivistas modernos, que por suas vez são tributários das filosofias orientais (NISHITANI, 1982; KALUPAHANA, 1986) e ocidentais (MERLEAU-PONTY, 1999) que defendem a tese de que a dualidade homem/mundo, mente/corpo, cognição/afeto surgiu da ignorância sobre a natureza das relações do organismo humano com o ambiente, não havendo sustentação para a tese cartesiana que postula um corpo que é pura matéria extensa e nem uma mente que é substância pensante.

Historicamente, a Ciência optou por ignorar o que poderia estar nesse "entre-deux" ou "caminho do meio", exposto por Merleau-Ponty (1999). Segundo ele, a ciência, ingenuamente, sempre pressupôs a mente e a consciência como epifenômenos do "mundo objetivo". De fato, esta tem sido uma das posturas extremas que a ciência tem adotado. O observador, retratado exemplarmente pela figura do físico no final do século XIX, era, com frequência, representado como um "olho desincorporado", fixando seu olhar objetivamente (quer dizer externamente) para o jogo dos fenômenos. Não obstante, os críticos dessa posição facilmente caíram no extremo oposto. O princípio da Indeterminação da 
mecânica quântica, por exemplo, foi com frequência utilizado para se aderir a um tipo de subjetivismo no qual a mente por si só “constrói” o mundo.

Quando nos voltamos para nós mesmos, para fazer de nossa própria mente nosso tema de reflexão, fazendo uso da atenção consciente ou incorporada, que é precisamente o que as visões integrais parecem fazer, nenhuma dessas posições - a que supõe um observador desincorporado ou a que supõe uma mente desterrada - é adequada. É possível perceber nas duas posturas a manutenção da tensão entre ciência e experiência.

Ir além dessas oposições constitui um desafio à reflexão contemporânea, pois nenhum dos extremos funciona para uma sociedade pluralista. Negar a efetividade de nossa própria experiência no estudo científico de nós mesmos não é apenas insatisfatório, corresponde a transformar o estudo científico de nós mesmos em um estudo sem objeto. No entanto, supor que a ciência não pode contribuir para uma compreensão de nossa experiência pode ser abandonar, no atual contexto, a tarefa da autocompreensão.

Varela, Thompson e Rosch, baseados nas ideias de Merleau-Ponty e de Nagarjuna, traçam um percurso de reflexão no qual é possível perceber a presença do "sujeito engajado" proposta nas perspectivas educacionais críticas. Tomando como exemplo um pesquisador refletindo sobre o que é ser humano, assim como Wallon, eles começam destacando os níveis mais básicos presentes nesta reflexão: a base biológica e as respostas por meio da conduta.

Esses autores dizem que é "somente porque essa estrutura, o cérebro, passa por interações em um ambiente, que podemos rotular a conduta resultante [...]”. Aqui estendemos "cérebro" como uma estrutura biológica. Assim, a pressuposição básica da reflexão engajada, e de um sujeito concreto e engajado, é que "podemos atribuir estruturas cerebrais específicas, mesmo que aproximadamente, a todas as formas de comportamento e experiência. E, inversamente, mudanças na estrutura cerebral se manifestam em alterações no comportamento e na experiência" (VARELA; THOMPSON; ROSCH, 2003, p. 27). Isso reafirma a noção de inseparatividade entre homem e mundo, presente na busca de síntese dialética walloniana.

Assim, no nível básico de uma reflexão engajada, há uma interdependência ou "especificação mútua" entre a estrutura biológica e o comportamento/ experiência. Nas palavras de Wallon teríamos desde o início a integração organismo meio.

Avançando nessa reflexão, percebemos que essas descrições de fenômenos, tanto biológicos quanto mentais, devem por sua vez ser produto da estrutura do nosso próprio sistema de reflexão. Existe uma interdependência entre o processo de descrição científica e a nossa própria estrutura reflexiva como pesquisador.

Quando estamos realizando esse processo reflexivo sobre a noção de 
"homem", fica claro que esse ato não surge do nada. "Nós nos encontramos realizando esse ato de reflexão a partir de um determinado background, no sentido heideggeriano, de crenças e práticas biológicas, sociais e culturais" (VARELA; THOMPSON; ROSCH, 2003, p. 28). Novamente temos a ideia de que as estruturas biológicas encontram-se irremediavelmente ligadas ao meio, aqui denominado de background.

Todo esse processo reflexivo não está ocorrendo mediante um "sobrevoo do pensamento", ele é engajado aqui e agora, enquanto o realizamos, como apontam Varela, Thompson e Rosch (2003, p. 28): “[...] nossa própria postulação de um tal background é algo que nós estamos fazendo; nós estamos aqui, seres vivos incorporados, assentados pensando nesse esquema todo, incluindo o que chamamos de background".

Varela, Thompson e Rosch (2003, p. 29) apontam que essa reflexão de forma engajada abre-se em "camadas que poderia continuar indefinidamente, como um desenho de Escher", contudo indica que o movimento de reflexão engajada "ao invés de somar camadas de abstração continuada", ou como Merleau-Ponty diria, fazer um "sobrevoo de pensamento", deveríamos "retornar para onde iniciamos, para a concretude e a particularidade de nossa própria experiência, mesmo no esforço da reflexão" (VARELA; THOMPSON; ROSCH, 2003, p. 29).

Assim, o desafio da educação da pessoa é estimular o processo de complementação continuado no giro dessa circularidade, de maneira que possamos ver "nossas atividades como reflexos de uma estrutura, sem perder de vista nossa experiência direta" (VARELA; THOMPSON; ROSCH, 2003, p. 29), ou seja, a integração dos conjuntos funcionais e suas relações continuadas com o meio.

Quando pensamos um sujeito engajado, com base nesta visão de educação voltada à integração walloniana, devemos nos atentar para a superação das ideias que supõem um observador desincorporado ou que supõem uma mente "desterrada (disworlded)" (VARELA; THOMPSON; ROSCH, 2003, p. 22). Nesse sentido, é fundamental a crítica aos três pressupostos básicos que sustentam uma visão desincorporada, a saber:

- Habitamos um mundo com propriedades particulares, como extensão, cor, movimento, som etc.

- Selecionamos ou recuperamos essas propriedades representando-as internamente.

- Existe um "nós" subjetivo separado que realiza essas tarefas.

Esses três pressupostos, juntos, constituem um compromisso forte, frequentemente tácito e inquestionável com o realismo ou o objetivismo/subjetivismo sobre a forma como é o mundo, sobre o que somos e como chegamos a conhecer o mundo. E recebeu extensiva crítica desde Nagarjuna (KALUPAHANA, 
1986) até Merleau-Ponty (1999), conforme já destacado anteriormente, e é fundamental para continuarmos pensando os processos de integração cognição e afetividade, pois:

Ao contrário do que propõe a tradição intelectualista do ensino, uma pedagogia inspirada na psicogenética walloniana não considera o desenvolvimento intelectual como a meta máxima e exclusiva da educação. Considera-a, ao contrário, meio para a meta maior do desenvolvimento da pessoa, afinal, a inteligência tem status de parte no todo constituído pela pessoa. (GALVÃO, 2007, p. 98).

Assim, podemos entender, a partir da "circularidade fundamental” de Varela, Thompson e Rosch, que o ato educativo não trata de aprender a representar um mundo preconcebido por uma mente preconcebida, mas, ao contrário, fala da atuação incorporada de um mundo e de uma mente com base em uma história de diversidade de ações desempenhadas por um ser no mundo. Na visão walloniana, os progressos da educação visam à mudança da sociedade e a formação de um sujeito engajado nessa proposta de mudança.

\section{Conclusão}

Apesar de sua premência e importância, ainda não se conseguiu estabelecer um corpo consistente de ações educativas, no tocante à questão da relação cognição e afetividade, que nos permita um enfrentamento desse desafio, permanecendo-se no nível de tentativas e projetos de intenções. Entre as causas que estão na raiz de nossa dificuldade de pensar essa problemática está o fato de não dispormos de modelos integrais de compreensão do humano pela reflexão pedagógica. Tratar dessas e de outras questões significa ocupar-se com temas complexos que não se esgotam numa primeira análise e abrangem uma multiplicidade de fatores e variáveis - biológicas, psicológicas, sociais, econômicas, culturais -, todas elas igualmente importantes. É preciso, portanto, estar atento para vencer as tentações do reducionismo bastante comum no campo educativo e psicológico.

Boaventura de Souza Santos (2000) usa a expressão "epistemologia da cegueira” para dizer das formas de representações da realidade distorcidas 
criadas e produzidas pela Modernidade, em que o ato de ver, muito parcialmente, é julgado como ver plenamente. Essa cegueira é o que nos impede de compreendermos as questões de fundo do campo pedagógico, e de aceitarmos aquilo que a experiência aponta: cognição e afetividade estão irremediavelmente presentes na formação da pessoa.

Não se trata de uma simples casualidade, haja vista que o projeto pedagógico da modernidade permanece tributário de certo entendimento sobre o sujeito, suas experiências e relação consigo, com os outros e com o próprio mundo.

Trata-se da compreensão substancialista que faz da Razão e de suas propriedades transcendentais o solo em que se movimentam as teorias pedagógicas. Tensionada entre as interferências do racionalismo cartesiano e do empirismo baconiano, o processo educativo permanece "cercado pela pedagogia do método e das técnicas de ensino como forma de assegurar a apropriação, pelo sujeito epistêmico, dos conteúdos culturais reproduzidos pela escola” (LIMA, 2003, p. 27).

No entanto, a experiência que estamos realizando, como educadores e como humanidade, é a do fracasso dessa forma de pensar e projetar as questões educativas. Entre as promessas não cumpridas e os déficits irremediáveis arrolados está a incapacidade desse modelo em estabelecer a própria autoconstituição dos indivíduos, referendada na subjetividade, como recurso fundamental em favor da pretensão emancipatória da educação moderna. É novamente Souza Santos (2000, p. 24) quem nos recorda que:

Enquanto no século XVIII morreram 4,4 milhões de pessoas em 68 guerras, no nosso século morreram 99 milhões de pessoas em 237 guerras. Entre o século XVIII e o século XX a população mundial aumentou 3,6 vezes, enquanto os mortos na guerra aumentaram 22,4 vezes. Depois da queda do Muro de Berlim e do fim da guerra fria, a paz que muitos finalmente julgaram possível tornou-se uma cruel miragem em face do aumento nos últimos 6 anos dos conflitos entre Estados e sobretudo dos conflitos no interior do Estado.

Nesse ponto, as contribuições de modelos de desenvolvimento integral, com suas visões engajadas, são fundamentais, pois não dissociam a relação cognição/afetividade, corpo/mente, teoria/prática e sujeito/objeto, apresentando-se assim como uma alternativa à meta educativa humana de privilegiar uma das "dimensões do ser humano como essencial e determinante de todas as outras", conforme destaca Röhr (2006, p. 1). Este último autor, em plena ressonância com 
Wallon, ainda indica que mesmo que seja difícil alcançar a meta da proposta de integralidade, ela não deve ser abandonada, pois a compreensão da pessoa como ser total nos conduz a um constante movimento produtor de transformações.

Nesse contexto, pensar a educação a partir da teoria walloniana pressupõe uma ruptura nas finalidades formativas dos sistemas educativos atuais. Isso é importante para marcar a posição que a educação não é um processo apenas intelectual, como aponta Gadotti (2000, p. 10), ela visa ao: "Desenvolvimento integral da pessoa: inteligência, sensibilidade, sentido ético e estético, responsabilidade pessoal, espiritualidade, pensamento autônomo e crítico, imaginação, criatividade, iniciativa. Para isso não se deve negligenciar nenhuma das potencialidades de cada indivíduo.”

Tendo a pessoa como o eixo articulador dos diversos conjuntos funcionais e de suas relações com o meio, a teoria walloniana permanece atual, capaz de dialogar com as contribuições recentes no campo das teorias psicológicas, como é o caso da "circularidade fundamental" de Varela, Thompson e Rosch, que aponta a possibilidade de pensarmos a formação do sujeito engajado, sem os extremos dualistas.

Assim, o desafio de qualquer proposta educativa apoiada nas reflexões wallonianas é não se tornar mais um instrumento de adequação das pessoas aos modelos perversos de opressão que imperam nas relações sociais baseadas nos modelos econômicos dominantes. De maneira que, os diversos saberes e aprendizagens que emergem das propostas integrativas não devem ser associados à ideia de desenvolvimento de um indivíduo qualificado e criativo para compor uma máquina perversa; isto distorceria a visão dialética, política e crítica de Wallon e não favoreceria a formação da pessoa engajada, que em última instância confunde-se com a noção de sujeito ético.

\section{REFERÊNCIAS}

COLL, C.; PALACIOS, J.; MARCHESI, Á. (Orgs.). Desenvolvimento psicológico e educação. Porto Alegre: Artes Médicas, 1995.

FERREIRA, A. L. Do entre-deux de Merleau-Ponty à atenção consciente do budismo e da abordagem transpessoal: análise de uma experiência de formação integral. $449 \mathrm{p}$. Tese (Doutorado em Educação) - Pós-graduação em Educação, Universidade Federal de Pernambuco. Recife, 2007. 
FOUCAULT, Michel. Vigiar e punir. Petrópolis: Vozes, 1995.

GADOTTI, M. Perspectivas atuais em educação. Porto Alegre: Artmed, 2000.

GALVÃO, I. Henri Wallon: uma concepção dialética do desenvolvimento infantil. Petrópolis: Vozes, 2007.

GOLEMAN, D. Inteligência emocional: a teoria revolucionária que redefine o que é ser inteligente. Rio de Janeiro: Objetiva, 1995.

KALUPAHANA, D. Nagarjuna: the philosophy of the middle way. Albany: State University of New York Press, 1986.

KIROUAC, G. Les émotions. In: RICHELE, M. et al. Traité de Psychologie Experimentale. Paris: PUF, 1994.

LIMA, J. F. L. A reconstrução da tarefa educativa. Porto Alegre: Mediação, 2003.

MAHONEY, A. A.; ALMEIDA, L. R. de. Afetividade e processo ensino-aprendizagem: contribuições de Henri Wallon. Psicologia da educação, v. 20, p. 11-30, 2005. ISSN 1414-6975.

MERLEAU-PONTY, M. Fenomenologia da percepção. São Paulo: Martins Fontes, 1999.

. La prose du monde. Paris: Gallimard, 1969.

. Um inédit de Merleau-Ponty. Revue de Métaphysique et de morale, n. 4, p. 401-406, 1962.

NISHITANI, K. La religión y la nada. Madri: Siruela, 2003.

RODRIGUES, N. Educação: da Formação Humana à Construção do Sujeito Ético. Educ. Soc., Campinas, v. 22, n. 76, 2001. Disponível em: <http://www. scielo.br/ scielo.php?script $=$ sci_arttext\&pid $=\mathrm{S} 0101-73302001000300013 \& \operatorname{lng}=\mathrm{en} \& \mathrm{nrm}=\mathrm{iso}>$. Acesso em: 10/05/2007.

RÖHR, F. Esclarecimento e reencarnação na "educação do gênero humano" de Gotthold Ephraim Lessing: uma hipótese em torno da questão da meta da formação humana. In: ENCONTRO DE FILOSOFIA DO NORTE E NORDESTE, FILOSOFIA EFORMAÇÃO HUMANA, 3., 2006, Recife. Anais.... 17 a 20 outubro, Recife, 2006. 1 CD-ROM.

SOUZA SANTOS, B. de. A crítica da razão indolente: contra o desperdício da experiência. São Paulo: Cortez, 2000.

VARELA, J. F.; THOMPSON, E.; ROSCH, E. Mente incorporada. São Paulo: Artes 
FERREIRA, A. L.; ACIOLY-RÉGNIER, N. M. Contribuições de Henri ...

Médicas, 2003.

WALLON, H. Do ato ao pensamento: ensaio de psicologia comparada. Petrópolis: Vozes, 2008.

A evolução psicológica da criança. São Paulo: Martins Fontes, 2007.

. As origens do pensamento na criança. São Paulo: Manole, 1986.

. Les origines du caractère chez l'enfant: les préludes du sentiment de personnalité. Paris: Boivin, 1934.

Texto recebido em 19 de novembro de 2009.

Texto aprovado em 12 de janeiro de 2010. 